\title{
A cervical tuberculous abscess mimicking a fourth branchial cleft cyst in a child: PCR, the key to fast diagnosis
}

\author{
Inès Riahi ${ }^{1 *}$, Rim Fradi $^{1}$, Habib Jaafoura ${ }^{1}$ and Lamia Kanzari ${ }^{2}$
}

\begin{abstract}
Background: Anterior cervical tuberculous abscess is a rare presentation of extrapulmonary tuberculosis even in endemic countries.

Case presentation: We report a case of a 14-year-old girl with a 5 day history of an anterior mass. The diagnosis of an infected fourth branchial cleft cyst was first evoked. Fine-needle aspiration cytology was suggestive of tuberculosis. Polymerase chain reaction analysis was the key to the diagnosis of a tuberculous abscess.

Conclusions: In endemic countries, abscesses occurring in uncommon sites should be dealt with a high degree of suspicion for tuberculosis. Early diagnosis is essential to initiate specific and effective treatment. Pre-operative diagnosis avoids invasive surgery and related complications.
\end{abstract}

Keywords: Extra pulmonary tuberculosis, Cervical tubercular abscess, Mycobacterium tuberculosis complex, GeneXpert ${ }^{\oplus}$ MTB/RIF

\section{Background}

The incidence of extrapulmonary tuberculosis (EPT) is on the rise in developing but also in industrialized countries. Cervical lymph nodes are the most commonly affected site [1]. EPT may have different clinical presentations making diagnosis difficult. Cervical tubercular abscess is a rare presentation of extrapulmonary tuberculosis. Its clinical presentation may be atypical requiring various investigations to make the diagnosis. Non-invasive fast diagnostic tools are helpful to reduce time to diagnosis with the probability of tuberculosis always in mind in endemic countries.

\section{Case presentation}

A 14-year-old girl presented with a 5-day history of an enlarging anterior mass of the neck. She had no

\footnotetext{
* Correspondence: ines.riahi.m@gmail.com

'ENT Department, Charles Nicolle Hospital of Tunis, Faculty of Medicine of

Tunis, Tunis El Manar University, 9 April Bd, 1006 Tunis, Tunisia

Full list of author information is available at the end of the article
}

difficulty in swallowing or breathing and no loss of appetite or weight.

She had no general symptoms such as asthenia, sweats, or fever. No social promiscuity or immune deficiency was identified. She also denied sore throat, cough, or sputum production. Her vaccination was complete for her age. Physical examination revealed a 4-cm firm mass in the right anterolateral part of lower neck. There were no inflammatory signs or tenderness. The mass was not mobile on protrusion of the tongue or swallowing. There was no cervical lymphadenopathy.

The biological assessment showed normal cell count and no signs of infection; TSH was $2.53 \mathrm{IU} / \mathrm{ml}$ and FT4 $1.11 \mathrm{ng} / \mathrm{dl}$. Tuberculosis skin test was negative. Ultrasonography showed a heterogeneous lesion over the right paramedian region of the neck, lateral to the thyroid lobe. Cervical CT scan showed a hypodense lesion with fluid attenuation and enhanced rim of the right paramedian space, lateral to the trachea and the thyroid lobe, extending to the ipsilateral paralaryngeal space with a mass effect on the esophagus (Fig. 1).

\section{Springer Open}

(- The Author(s). 2020 Open Access This article is licensed under a Creative Commons Attribution 4.0 International License, which permits use, sharing, adaptation, distribution and reproduction in any medium or format, as long as you give appropriate credit to the original author(s) and the source, provide a link to the Creative Commons licence, and indicate if changes were made. The images or other third party material in this article are included in the article's Creative Commons licence, unless indicated otherwise in a credit line to the material. If material is not included in the article's Creative Commons licence and your intended use is not permitted by statutory regulation or exceeds the permitted use, you will need to obtain permission directly from the copyright holder. To view a copy of this licence, visit http://creativecommons.org/licenses/by/4.0/. 


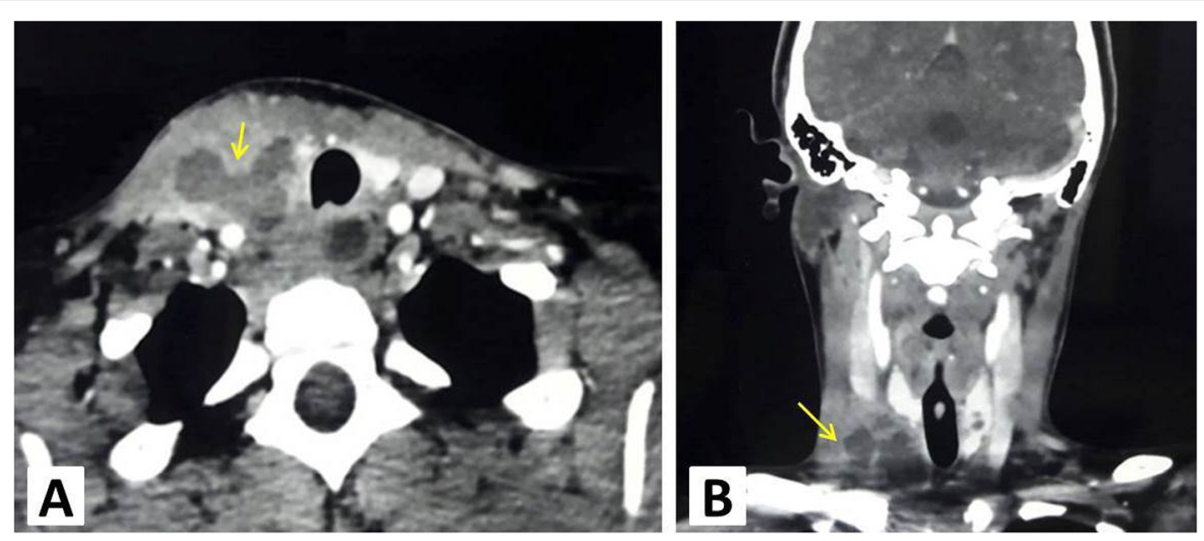

Fig. 1 a Axial view and $\mathbf{b}$ coronal view showing a hypodense lesion (arrows) with fluid attenuation and enhanced rim, in the midline, right paramedian, and posterior plane

The diagnosis of infected cyst of the fourth branchial cleft was first evoked, but the atypical presentation and the negative infectious biological balance incited to further investigations.

The fine-needle aspiration cytology (FNAC) of the swelling revealed the presence of Langerhans giant cells along with an epithelioïd granuloma that was suggestive of tuberculosis. A quick additional argument in favor of the diagnosis was needed to confirm the diagnosis justifying a long and potentially aggressive medical treatment and avoid an invasive surgery.

The PCR GeneXpert ${ }^{\circ}$, performed on the puncture fluid, detected Mycobacterium tuberculosis complex and no rifampicin resistance.

As a result, surgical drainage of the abscess was no longer indicated, and the patient was started on antituberculous therapy. Microbiological culture was positive for Mycobacterium tuberculosis complex, and the diagnosis of tuberculous abscess was confirmed.

The patient received weight-adjusted doses of isoniazid $(\mathrm{H})$, rifampicin $(\mathrm{R})$, pyrazinamide $(\mathrm{Z})$, and ethambutol $(\mathrm{E})$ for 2 months, followed by $\mathrm{H}$ and $\mathrm{R}$ for a duration of 6 months. The swelling totally disappeared at the end of the second month of treatment.

Patient did not present any complications of antituberculous drugs. There was no recurrence or reactivation of the disease at 10-months follow-up.

\section{Discussion}

Tuberculosis (TB) remains one of the biggest health problems in developing and industrialized countries [2] with extrapulmonary tuberculosis (EPT) representing an increasing proportion reaching 20 to $40 \%$ [3].

In Tunisia, the incidence of EPT is also on the rise and a growing interest in EPT is observed [3]. The most common site of extrapulmonary disease is lymph node especially the cervical group (60-90\%).
The incidence of tuberculosis in children has been continuously rising around the world. EPT cases account for one third of these instances $[4,5]$.

EPT may have different clinical presentations rendering the diagnosis difficult compared to pulmonary tuberculosis. An estimated one third of new cases remain undiagnosed every year [3]. The treating clinicians should be aware of all the rare presentations of the disease $[4,6]$.

Anterior cervical swelling may suggest different etiologies such as branchial cysts, inflammatory and infectious lymphadenitis, and neoplastic causes [7]. The anterior lymph node group may mimic a thyroid nodule or a thyroglossal cyst [8].

When indicated, an ultrasound is the first-line radiological examination. Tuberculous node appears as a hypoechogenic lesion, with intranodal cystic calcifications and necrosis that is dense with posterior acoustic shadow. On CT scan, the lesions may appear homogeneous, entirely calcified, or have a low-attenuation central zone and an enhancing rim [9].

FNAC has a high diagnostic accuracy in detecting tuberculosis with sensitivity of $93.1 \%$ and specificity of $100 \%$. Cytological criteria include clusters of epitheloid cells with or without necrotic debris, mature lymphocytes, and pleomorphic lymphoid cells [10].

The absence of specific clinical presentations and high morbidity rates caused by diagnostic difficulties and delays make the use of new diagnostic tools necessary. Mycobacterial culture which is the gold standard method for TB diagnosis has a long incubation period (2-8 weeks) and a low sensitivity. Faster diagnostic techniques are essential to initiate specific and effective treatment. Molecular diagnostic tools such as GeneXpert $^{\circ}$ can detect mycobacterium complex as well as resistance to rifampicin. According to Marouane et al., the sensitivity of the GeneXpert ${ }^{\circ}$ test was $87.5 \%$ in biopsies, 
$80 \%$ in pus and abscesses, and $66.7 \%$ in biological fluids [3]. This test helped us reduce time to diagnosis in front of an atypical acute presentation and avoid an invasive surgical procedure.

A patient with a neck swelling not responding to antibiotics should receive a puncture with PCR study and FNAC, if tuberculosis is suspected, prior to further investigation by invasive procedures such as surgical biopsy [11].

Only a few cases of cervical tuberculous abscesses have been reported. We diagnosed this case preoperatively thanks to FNAC and PCR.

\section{Conclusion}

The occurrence of abscesses in uncommon sites should be dealt with high degree of tuberculosis suspicion in endemic countries. Pre-operative diagnosis avoids invasive surgery and related complications.

\section{Abbreviations \\ PCR: Polymerase chain reaction; EPT: Extrapulmonary tuberculosis; TSH: Thyroid-stimulating hormone; FT4: Free thyroxine (T4); CT scan: Computed tomography scan; FNAC: Fine-needle aspiration cytology (FNAC); H: Isoniazid; R: Rifampicin; Z: Pyrazinamid; E: Ethambutol}

\section{Acknowledgements}

"Not applicable" for this section.

\section{Authors' contributions}

IR concepted and designed the manuscript content and supervised manuscript preparation, editing and review. RF analyzed and interpreted the patient data regarding the cervical disease and was a major contributor in writing the manuscript. $\mathrm{HJ}$ contributed to literature search and manuscript review. LK supervised and validated the bacteriological data relating part. All authors read and approved the final manuscript.

\section{Funding}

No funding

\section{Availability of data and materials}

The datasets used and analyzed during the current study are available from the corresponding author on reasonable request.

\section{Competing interest}

The authors declare that they have no competing interests

\section{Ethics approval and consent to participate}

Our institution does not require ethical approval for reporting individual cases or case series. Written informed consent was obtained from the parents for the scientific use of the child's medical data.

\section{Consent for publication}

Written informed consent was obtained from the parents for their child's anonymized information to be published in this article.

\section{Author details}

${ }^{1}$ ENT Department, Charles Nicolle Hospital of Tunis, Faculty of Medicine of Tunis, Tunis El Manar University, 9 April Bd, 1006 Tunis, Tunisia. ${ }^{2}$ Microbiology Laboratory, Charles Nicolle Hospital of Tunis, Faculty of Medicine of Tunis, Tunis El Manar University, Tunis, Tunisia.
Received: 27 April 2020 Accepted: 11 June 2020

Published online: 28 August 2020

\section{References}

1. Omura S, Nakaya M, Mori A, Oka M, Ito A, Kida W et al (2016) A clinical review of 38 cases of cervical tuberculous lymphadenitis in Japan - the role of neck dissection. Auris Nasus Larynx. 43(6):672-676

2. Moure A, Munoz L, Torres M, Santin M, Martín R, Alcaide F (2011) Rapid detection of mycobacterium tuberculosis complex and rifampin resistance in smear-negative clinical samples by use of an integrated real-time PCR method. J. Clin Microbiol 49(3):1137-1139

3. Marouane C, Smaoui S, Kammoun S, Slim L, Messadi-Akrout F (2016) Evaluation of molecular detection of extrapulmonary tuberculosis and resistance to rifampicin with GeneXpert ${ }^{\circledR}$ MTB/RIF. Med Mal Infect. 46(1):20-24

4. Rieder HL (2013) The enigma of extra-pulmonary tuberculosis. Int J Tuberc Lung Dis. 17(2):144

5. Meier JD, Grimmer JF (2014) Evaluation and management of neck masses in children. Am Fam Physician. 89(5):353-358

6. Adada H, Valley MA, Nour SA, Mehta J, Byrd RP, Anderson JL et al (2014) Epidemiology of extra-pulmonary tuberculosis in the United States: high rates persist in the post-HIV era. Int J Tuberc Lung Dis. 18(12):1516-1521

7. Khalil EA, Elsiddig KE, Elsafi ME, El-Hag IA, Elkhidir IM, Suleiman G et al (2000) Supra-sternal notch tuberculous abscess: a report of three cases. Trans R Soc Trop Med Hyg. 94(1):58-60

8. Baskota DK, Prasad R, Kumar Sinha B, Amatya RC (2004) Distribution of lymph nodes in the neck in cases of tuberculous cervical lymphadenitis. Acta Otolaryngol. 124(9):1095-1098

9. Reddy SG, Daggolu J (2016) Pretracheal tuberculous abcess mimicking a thyroid swelling-a case report. Int J Surg Case Rep. 28:352-354

10. Muyanja D, Kalyesubula R, Namukwaya E, Othieno E, Mayanja-Kizza H (2015) Diagnostic accuracy of fine needle aspiration cytology in providing a diagnosis of cervical lymphadenopathy among HIV-infected patients. Afr Health Sci. 15(1):107-116

11. Vijay $V$, Vaishya R. Tuberculous suprasternal notch abscess in a child. BMJ Case Rep. 2016;2016:https://doi.org/10.1136/bcr-2015-214269.

\section{Publisher's Note}

Springer Nature remains neutral with regard to jurisdictional claims in published maps and institutional affiliations.

\section{Submit your manuscript to a SpringerOpen ${ }^{\circ}$ journal and benefit from:}

- Convenient online submission

- Rigorous peer review

- Open access: articles freely available online

- High visibility within the field

- Retaining the copyright to your article

Submit your next manuscript at $>$ springeropen.com 